\title{
Manejo conservador en múltiples heridas torácicas por bala*
}

\author{
Drs. MARCELO PARRA N. ${ }^{1}$, JOSÉ ORTEGA S. ${ }^{1}$, RAÚL BERRÍOS S. ${ }^{1}$, \\ RAIMUNDO SANTOLAYA C. ${ }^{1}$, PHILIPP SCHWEMBER R. ${ }^{2}$ \\ 1 Equipo de Cirugía de Tórax, Hospital Padre Hurtado, Facultad de Medicina Clínica Alemana- \\ Universidad del Desarrollo. \\ 2 Interno Facultad de Medicina Clínica Alemana-Universidad del Desarrollo. \\ Santiago, Chile.
}

\section{Conservative management in multiple thoracic gunshot wounds}

Hombre de 30 años de edad que ingresa al Servicio de Emergencia Adulto del Hospital Padre Hurtado con heridas torácicas por balas. Tras la instalación de pleurostomías 28FR en ambos hemitórax, se realiza una Rx de Tórax portátil, mostrando 5 balas torácicas (Figura 1). Debido a la estabilidad del paciente se solicita un Angio-TC de Tórax. En éste, destacaba una extravasación contenida de contraste en la región de la arteria apical del lóbulo superior izquierdo (Figura 2a) y otras lesiones menores. El paciente se mantuvo hemodinámicamente estable durante el seguimiento y con bajo débito por las pleurostomías. Un nuevo Angio-TC de Tórax $48 \mathrm{~h}$ post admisión, mostraba que la lesión del lóbulo superior izquierdo que extravasaba contraste ya no estaba presente, correspondiendo por lo tanto, a una hemorragia parenquimatosa y no a una lesión de una arteria del lóbulo superior izquierdo (Figura 2b). El paciente fue dado de alta sin complicaciones posteriores.

El manejo conservador es una opción para los traumatismos torácicos por bala. Un seguimiento estricto es necesario, ya que algunas veces el manejo conservador falla. El Angio-TC de Tórax es una herramienta rápida y sensible, necesaria para realizar un manejo conservador en estos pacientes ${ }^{1-3}$.

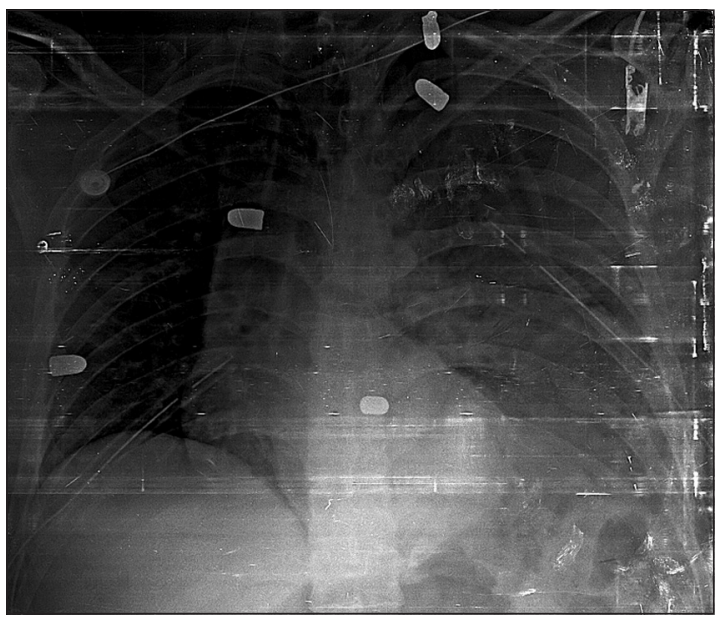

Figura 1. Radiografía de Tórax portátil después de instalación de pleurostomía bilateral. Se evidencian 5 balas torácicas y pleurostomía bilateral. Persiste neumotórax a izquierda.

*Recibido el 10 de diciembre de 2012 y aceptado para publicación el 12 de febrero de 2013.

Este trabajo fue presentado en: 20th European Conferences on General Thoracic Surgery. European Society of Thoracic Surgeons. Essen, Alemania. 10 al 13 de junio de 2012.

Los autores no refieren conflictos de interés.

Correspondencia: Dr. Marcelo Parra N.

Esperanza 2150, 5to Piso. San Ramón, Santiago, Chile.

mfparra@gmail.com 

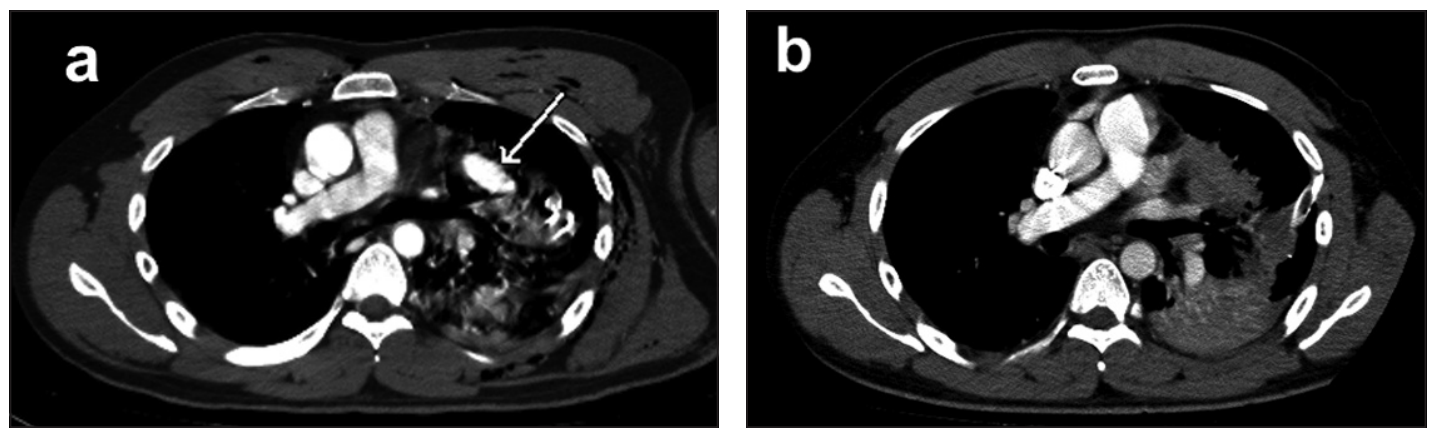

Figura 2. a) Angio-TC de Tórax al ingreso, la flecha señala la extravasación contenida de medio de contraste en el lóbulo superior izquierdo. b) Angio-TC de Tórax a las 48 h sin extravasación de contraste.

\section{Referencias}

1.- Quartey B, Jessie E. Pulmonary artery and vein pseudoaneurysm after gunshot wound to the chest. J Emerg Trauma Shock 2011;4:313-6.

2.- Shanmuganathan K, Matsumoto J. Imaging of penetra- ting chest trauma. Radiol Clin North Am. 2006;44:22538 .

3.- O'Connor JV, Scalea TM. Penetrating thoracic great vessel injury: impact of admission hemodynamics and preoperative imaging. J Trauma 2010;68:834-7. 